\title{
IDENTIDAD Y NOSTALGIA: EL DISCURSO DE VOX A TRAVÉS DE TRES ESLÓGANES
}

\section{IDENTITY AND NOSTALGIA: THE VOX DISCOURSE THROUGH THREE SLOGANS}

\section{Pedro FERNÁNDEZ RIQUELME}

(Universidad de Murcia)

\section{Resumen}

A través del estudio semántico-pragmático de tres eslóganes correspondientes a tres campañas electorales consecutivas, estableceremos el tipo de discurso de Vox y su pertenencia o no a determinadas familias políticas vinculadas con la nueva derecha identitaria y la extrema derecha. Además, demostraremos cómo los términos de sus eslóganes pueden participar de dos familias léxicosemánticas: la identidad y la nostalgia.

Palabras clave: extrema derecha; franquismo; campaña electoral: pragmática; semántica; discurso.

\footnotetext{
Abstract

The type of discourse used by Vox and its possible or not belonging to some political families linked to the new identitarian right and extreme right ideology will be here analysed through the semantic-pragmatic study of three slogans related to three consecutive political campaigns. In addition, it will be proved that the
} 
words employed in its slogans may belong to two lexical-semantic families: identity and nostalgia.

Keywords: extreme right; franquismo; electoral campaign,pragmatics; semantics; discourse.

\section{Introducción}

Vox nació como partido político en 2013, cuando algunos antiguos afiliados y dirigentes del Partido Popular, que ocupaba casi hegemónicamente el espectro del centro derecha español en su ámbito nacional, salieron de sus filas por discrepancias con las políticas tomadas por dicha organización en torno al proceso independentista catalán y por la erosión de la corrupción interna. Cuando Santiago Abascal, su actual líder, es elegido presidente de Vox, tres de sus fundadores abandonan la formación por su alineamiento con el catolicismo, el euroescepticismo, el proteccionismo económico y el nacionalismo (Fábregas, 2018). La finalidad inicial del partido de recoger el voto del ala más conservadora de la derecha que estaba desencantada con el gobierno de Rajoy (Sangiao, 2018) se transforma para construir una nueva derecha en España. Desde su fundación hasta las elecciones a la Junta de Andalucía en diciembre de 2018, Vox no obtuvo representación institucional en los comicios celebrados a nivel autonómico, estatal o europeo. La candidatura de Vox en dichas elecciones andaluzas obtuvo doce escaños y cerca del $11 \%$ de los votos. Un estudio del diario El País destacaba que esta formación obtuvo mayor éxito en los municipios con una mayor inmigración de fuera de la Unión Europea (Llaneras, 2018). En las últimas elecciones generales de 10 de noviembre de 2019, Vox alcanza su máximo hasta la fecha: 3.640.063 votos (15,09\%). Jamás desde la recuperación de la democracia en España un partido a la derecha del PP lograba estas cifras.

Uno de nuestros objetivos será poder vincular a través del discurso de Vox su adscripción a una corriente política existente en Europa y América, partiendo del análisis de los tres eslóganes correspondientes a las tres últimas campañas 
de las elecciones generales. La motivación parte de la negación constante de Vox a ser identificados con el calificativo político de "extrema derecha" que se le atribuye desde diferentes medios de comunicación (Cachero, 2018) y partidos políticos (García, 2019). Vox usa la ironía para dar la vuelta a la acusación ("Somos de extrema necesidad"1) consciente del estigma que supondría su deliberada adscripción a esta corriente política, a la que los partidos políticos europeos aíslan en las instituciones, como pueden ser los casos de Francia o de Alemania; pero no así en Finlandia, Dinamarca, Austria o Italia, aunque estas coaliciones han durado poco en el tiempo y han estado enmarcadas en la polémica constante (Carbajosa, 2019). Por tanto, entendemos que hay una necesidad de esclarecimiento en cuanto a su filiación política-ideológica que va más allá de un artículo de investigación, pues habría que analizar argumentarios, declaraciones de sus líderes, programas electorales, ejecución de medidas, etc., pero podemos poner de manifiesto, a través de su discurso icónico, como es el eslogan electoral, una serie de significados que los pueden vincular a partidos y corrientes políticas ya existentes.

Para llegar a tal objetivo, usaremos una metodología basada en el análisis semántico-pragmático de los eslóganes, donde los elementos léxicos y su vinculación con el contexto y la historia nos ayudarán a la caracterización discursiva. Utilizaremos la teoría de H. P. Grice (1975) sobre las implicaturas. Se entiende por implicatura una información que el emisor de un mensaje trata de hacer manifiesta a su interlocutor sin expresarla explícitamente. La división en implicaturas conversacionales generalizadas y particularizadas, dada su menor o mayor dependencia del contexto, se antoja esencial para los objetivos marcados en este artículo.

Tras Grice, un paso importante en la pragmática fue la teoría de la relevancia de Sperber y Wilson (2004). Lo primero que cabe apuntar es la doble vertiente - cognitiva y comunicativa - sobre la que descansa la relevancia; por una parte, se trata de una teoría que tiene en cuenta la cognición humana, dado

\footnotetext{
${ }^{1}$ https://twitter.com/lanoche_24h/status/1098336372442558464?lang=es.
} 
que un supuesto (o enunciado) es relevante cuanto mayor sea su efecto cognitivo o contextual y menor su esfuerzo de procesamiento. Para que un supuesto o enunciado sea relevante es necesario recurrir al contexto, puesto que la relevancia o pertinencia no es una característica propia de los enunciados, sino que surge a partir de la relación entre el enunciado y el contexto (Escandell, 1996: 120). No obstante, cabe mencionar que el contexto no es algo fijo y predeterminado, sino que es el destinatario del mensaje quien lo amplía con el objetivo de lograr la interpretación más adecuada con la intención del emisor. El contexto también es aquel conjunto de conocimientos compartidos por los interlocutores en un intercambio verbal, y que resultan necesarios a la hora de comunicarnos.

Por consiguiente, la relevancia guarda relación con la intención comunicativa del hablante en tanto en cuanto se sobreentiende que el emisor siempre va a pretender que su información resulte relevante para el destinatario. Este último, a su vez, decide si la información es relevante a partir del esfuerzo de procesamiento que conlleve dicho enunciado, así como los efectos que este tenga en el contexto.

En definitiva, como se apuntaba líneas atrás, la teoría de la relevancia incide en que la «característica esencial de la mayor parte de la comunicación humana es la expresión y el reconocimiento de intenciones» (Sperber y Wilson, 2004: 238)

Dos de estos tres eslóganes electorales de Vox son muy cortos y lacónicos y, sin embargo, tras el proceso de inferencia observaremos que el sentido que implica es harto revelador de la ideología de Vox y sus intenciones. Intentaremos responder, pues, si pertenece a una nueva categoría política o pertenece a una corriente derechista-identitaria ya existente.

Siguiendo con la pragmática, también usaremos el concepto de acto de habla y fuerza ilocutiva de Austin (1962) y de Searle (1969). Los actos ilocutivos tienen fuerza, pues toda expresión, en cuanto utilizada con ciertos fines $u$ objetivos comunicativos, tiene una determinada fuerza, que es preciso distinguir, por una parte, del significado, que está ligado al acto rético, y, por otra, de las 
consecuencias o los efectos que el uso de las expresiones pueda causar en un auditorio (acto perlocutivo). En ocasiones, la fuerza (o intención) de una expresión lingüística se hace explícita a través de uno u otro recurso gramatical o textual. Cuando así sucede, la expresión contiene una indicación suficiente de "cómo hay que tomarla", por utilizar la expresión de Austin.

Ante la reciente aparición de Vox en la escena parlamentaria, la bibliografía es todavía escasa, por este motivo hemos usado referencias de la prensa digital como fuentes actuales para completar el análisis llevado a cabo en este artículo.

\section{Vox y su filiación ideológica}

Los partidos pertenecientes a la extrema derecha europea como el Front National (Francia, ahora llamado Rassemblement National), Alternative für Deutschland (Alemania) o la Lega (Italia) recogen en varios de sus eslóganes electorales el nombre de su país. En el AFD (Alemania) es más difícil encontrarlo porque el nombre del propio partido ya contiene el topónimo de su nación, sin embargo, existe aun siendo redundante (figura 8).

Como veremos más adelante en unas declaraciones de Abascal, Vox distingue entre globalistas y patriotas, coincidentemente con el Front National francés (Fernández, 2019) y con Donald Trump (Guimón, 2019). Este alineamiento se ha hecho fuerte gracias al trabajo de Steve Bannon, antiguo asesor de Trump e ideólogo de la derecha identitaria a la que quiere unir bajo una especie de organización internacional llamada The Movement (EI Movimiento) (Hosenball, 2018), aunque parece que no está teniendo el éxito esperado, pues estos partidos siguen poco cohesionados y con poca fuerza en el Parlamento Europeo (Gil, 2019). En Europa, se relaciona con "derecha identitaria" a las nuevas fuerzas políticas que cuestionan, desde posiciones conservadoras y nacionalistas, el orden europeo actual (González Cuevas, 
2009a) y rechazan la multiculturalidad (Charaudeau, 2009), haciendo de una determinada identidad (raza, religión, origen geográfico) su eje político.

En la progresiva evolución hacia posiciones alejadas del centro-derecha, que llevó a varios destacados fundadores a marcharse del partido, Ferreira (2019: 77) señala un punto de inflexión:

En el proceso de asalto a las instituciones, especialmente desde que Abascal se consolidó como líder del partido, Vox fue radicalizándose de forma progresiva (Casals, 2018). El punto de inflexión se produjo el 22 de enero de 2017, cuando la nueva formación política participó en el encuentro de la derecha populista radical europea en Alemania junto con Marine Le Pen, Frauke Petry o Geert Wilders. En abril de 2018 se reunieron también con Steve Bannon, jefe de estrategia de Donald Trump, quien claramente identificó a Vox con la tendencia de la nueva derecha en Europa

A pesar de que hay autores que establecen que estos partidos pertenecen a nuevas categorías políticas superadoras del binomio izquierda-derecha (González Cuevas, 2019a y b), recientes estudios vinculan el discurso de Vox con el de la ultraderecha española de los años 30, quienes a su vez se inspiraban en elementos ideológicos de los siglos XV y XVI españoles vinculados al fin de la Reconquista (Fernández y Segovia, 2019), basándose en los siguientes tópicos:

- Recuperación de un supuesto pasado glorioso

- Enemigos de España (ahora nacionalistas periféricos e izquierdistas)

- Unidad religiosa e idiomática

- Defensa del patriarcado (ahora antifeminismo)

Del mismo modo, el Front National francés llama a estar orgullosos de todo el pasado histórico de su país, incluyendo el gobierno colaboracionista con los nazis de Pétain (Fernández, 2019). 
Decenas de etiquetas han sido aplicadas a este tipo de partidos: extrema derecha, ultraderecha, derecha radical, derecha identitaria, incluso neofascistas (Cas Mudde, 2000). En Ferreira (2019) se listan hasta diez características esenciales de la derecha radical:

- Nacionalismo extremo,

- etnocentrismo,

- anticomunismo,

- antiparlamentarismo,

- antipluralismo,

- militarismo,

- ley y orden,

- exigencia de un líder político fuerte y/o ejecutivo,

- antiamericanismo y pesimismo cultural.

El fracaso de Bannon al intentar unirlos en esa especie de "Internacional" identitaria y antiglobalista también se debe a que no son totalmente homogéneos. Por ejemplo, Vox es un partido cercano al confesionalismo ultracatólico (Bastante, 2018) con lo que eso implica frente a los derechos LGTBI o al aborto, mientras que el Front National y el AFD no solo no van explícitamente contra este colectivo, sino que lo integra entre su aparato dirigente (Fernández, 2019). Igualmente, el discurso de Vox está "más próximo al neoliberalismo de los ultras latinoamericanos que al discurso obrerista de Salvini o Le Pen”, según afirma Rodríguez Palop (2019). Analizando fragmentos del discurso de Vox, Ferreira (2019: 85) localiza elementos ideológicos que coinciden con los que venimos exponiendo:

La España Viva quiere libertad con mayúsculas, libertad para disfrutar del fruto de nuestro esfuerzo sin que un político nos lo 
confisque para pagar traducciones en el Senado cuando todos nos entendemos en una lengua común.

Aquí Abascal "proyecta un nacionalismo español muy claro al defender la hegemonía del castellano frente a les demás lenguas del Estado" (Ferreira, 2019: 85). El uso de las otras tres lenguas cooficiales en España (catalán, euskera y gallego) tiene que ver con la presencia de partidos nacionalistas, tanto de izquierdas como de derechas, en las instituciones del Estado, lo que es criticado por Abascal en este fragmento, pero en general Vox los considera "enemigos de España”, recuperando esa retórica de los años 30, previa a la Guerra Civil, de la que ya hemos hablado. Incluso han pedido que se ilegalicen algunos de estos partidos (Fernández y Segovia, 2019: 9).

Ferreira (2019: 84) sigue tres categorías propuestas por Cas Mudde para analizar si Vox cumple o no determinadas características para ser incluido en el conservadurismo, en la derecha radical o en la extrema derecha.

\section{Tabla 1}

Caracterización ideológica de Vox. Ferreira (2019)

\begin{tabular}{|l|c|c|c|}
\hline Características & Derecha Radical & Extrema Derecha & Conservadurismo \\
\hline Nacionalismo & Sí & Sí & Sí \\
\hline Nativismo & Sí & Sí & NO \\
\hline Autoritarismo & Sí & Sí & Sí \\
\hline Antidemocracia & NO & Sí & NO \\
\hline Populismo & - & - & Sí \\
\hline Valores & - & - & \\
\hline tradicionales & & & Sí \\
\hline Neoliberalismo & - & - & \\
\hline
\end{tabular}

El guion (-) significaría que la presencia o ausencia de un determinado elemento no es relevante para la clasificación. Discrepamos profundamente de Ferreira en la característica relativa al neoliberalismo, pues es fundamental 
entender que los partidos de la derecha radical, donde según este autor se ubicaría Vox, asumen el capitalismo, pero no estrictamente en su forma de libertad de mercado global (neoliberalismo) sino de defensa de las élites empresariales locales (Soriano, 2020) frente a las trasnacionales, aunque con más desregulación (Antequera, 2019) y privatizaciones (Rodríguez, 2019). E proteccionismo (Llamas, 2018) sería una de las medidas económicas a desarrollar por estos partidos o líderes (Trump. Front National, etc). Aunque el propio autor deja una clara afirmación sobre la adscripción económica de Vox pues "presenta una desacomplejada agenda neoliberal en términos económicos" (Ferreira, 2019: 94). Vox se inscribiría, como hemos dicho, en la derecha radical porque "presenta tintes iliberales en relación con el pluralismo político o a la protección de las minorías, pero no propone la instauración de un régimen autocrático ni hace un uso habitual y sistemático de la violencia" (Ferreira, 2019: 94). Fernández y Segovia (2019) analizan la violencia discursiva de Vox en paralelo a la ejercida por las derechas durante la II República, que abonó el terreno para la violencia del golpe de estado². Estos autores ven a Vox en el extremo ideológico de la derecha:

Su intransigencia, su exaltación de la tradición y la moral, su racismo, intolerancia y machismo les sitúan más allá de la derecha tradicional, pero es su discurso y la construcción de supuestos enemigos irreconciliables, lo que le sitúa aún más al extremo de la derecha

(Fernández y Segovia: 2019: 9)

Para López Corhero (2019) Vox pertenece al movimiento populista "con tintes claros de ultraderecha", achacables a su programa como el "énfasis del control de "las paredes de vuestro (las fronteras de España) hogar", la propuesta de supresión de la Ley de Igualdad de Género, la supresión del Estado de las autonomías ("España una y no 17"), etc.". Como diría Charaudeau (2009: 256): "lo que aquí se trata es del análisis del discurso populista, y no del populismo, aunque esto no impide que nos interroguemos sobre las relaciones entre lenguaje y acción, entre retórica discursiva y modo de gobernanza”. Si seguimos los parámetros del autor francés, Vox encajaría en el perfil de partido populista

${ }^{2}$ Golpe contra el Gobierno de la II República preparado por un grupo de militares que desembocó en la Guerra Civil de España (1936-1939). 
(identidad nacional, victimización, enemigo interior/adversario, enemigo exterior...)

\section{Análisis lingüístico de los eslóganes}

Los tres eslóganes seleccionados por Vox para representarlo en las tres últimas convocatorias estatales han sido:

- "Hacer España grande otra vez" (Elecciones generales de 26 de junio de 2016). Figuras 1 y 2.

- "Por España" (Elecciones generales de 28 de abril 2019). Figuras 4 y 5

- "España siempre" (Elecciones generales de 10 de noviembre 2019). Figura 3.

La repetición del término España en los tres eslóganes aparece entre las técnicas de la propaganda porque "desde el punto de vista psíquico es necesaria la reiteración de la sensación para que la imagen quede registrada y deslindada en la memoria" (Fabregat, 1961: 126). La continua aparición de esta palabra en los mítines, arengas, eslóganes, etc. de Vox es útil y efectiva a nivel propagandístico, pues la reiteración parece provocar un juicio de valor en el cuadro de las oposiciones sociales (Fabregat, 1961: 127), restando valor a las aportaciones a la política de Estado del resto de formaciones políticas, que serían, por tanto, menos patrióticas. La repetición de la palabra España en los textos de Vox tiene la intención de estar permanentemente en los medios de comunicación, que funcionan como altavoces ante la opinión pública (Chomsky y Herman, 1988) y enmarcar el debate (Lakoff, 2007), restringiendo el campo de la conciencia a los motivos elegidos por el propagandista (Fabregat, 1961: 129). El sistema mantiene la reiteración propagandística, aumentada hoy por la inmediatez, la hiperconectividad y multidifusión de las redes sociales (Gallardo, 2018), formando un ambiente en torno a la marca España, y nos habituamos a 
él, pues en esa red de conexiones cotidianas el hombre suele hallar cierta seguridad; cierto sentido de la verificación (Fabregat, 1961: 131-132). Si observamos las figuras 1, 2, 3 y 5, la bandera nacional insiste en la misma idea, reiterándola con la palabra y la imagen.

Mencionar a "España" como único elemento propagandístico significa que Vox transfiere a una entidad abstracta las propias ideas, conveniencias o actitudes (Fabregat, 1961: 144), pues España como Estado concreto incluye a todos aquellos que el partido de Abascal denomina "enemigos de la patria" (Fernández y Segovia, 2019). Mediante el concepto de transferencia, el propagandista da por supuesto que va a hablar de algo que comparten todos 0 la gran mayoría (Fabregat, 1961: 146).

La palabra "España" pertenece a la categoría de los sustantivos propios, pues designa un país. Al ser un topónimo, indica un lugar o espacio geográfico que podemos situar en un mapa. Sin embargo, nos detendremos en el uso que Vox hace de España como idea, como concepto fuera de la delimitación estrictamente geográfica. Esta concepción no es nueva, pertenece a la idea de nación en el pensamiento reaccionario español (Soto, 2017), el cual tiene una larga tradición incluyendo muy especialmente la época de Franco (Giménez, 2015). Al hablar del pensamiento del filósofo García Morente, Soto (2017: 232233) lo relaciona con el pensamiento tradicionalista y antimoderno clásico español, del que ya había tratado Ramiro de Maeztu para la dictadura de Primo de Rivera:

La historia de España se convertirá en Filosofía de la Historia, y, por tanto en la búsqueda y continuación de su "esencia eterna". Se pretenderá un vaciamiento del Estado Moderno, en provecho de la resurrección de un mundo medieval.

Esta concepción es producto del fracaso de las revoluciones liberales del siglo XIX en España, por lo que el catolicismo y la nación serán los dos polos del pensamiento antiliberal y conservador español (Soto, 2017: 236-237) 
Durante el franquismo, "el bando rebelde se hizo pronto con el control del discurso nacionalista, fiel a una visión conservadora del mismo", convergiendo en ella el nacionalismo regeneracionista, el catolicismo tradicionalista y el fascismo (Giménez, 2015: 15). La aportación del fascismo de Falange fue muy importante pues, siendo así afín al nazismo alemán y al fascismo italiano, incluyó la "voluntad de imperio". Esto supuso en la práctica que "el régimen suprimió los estatutos de autonomía y rescató la fraseología joseantoniana para definir a España como «unidad de destino en lo universal» (Giménez, 205: 15-16). Los pensadores reaccionarios españoles como Maeztu y José Antonio Primo de Rivera entienden que la sublevación "es la manifestación histórica de la existencia de la esencia eterna de España. Una esencia eterna que se manifiesta en el campo de las ideas" (Soto, 2017: 242).

Giménez (2015: 24-25) rescata declaraciones del propio general Franco donde justifica el golpe de estado contra el gobierno de la II República y la posterior Guerra Civil:

Para Franco, el «sistema liberal parlamentario de partidos» no había traído más que inestabilidad política y divisiones entre los españoles, además de la pérdida del imperio. El liberalismo era, según el «Caudillo», una farsa extranjerizante que, controlada por unos cuantos oligarcas, había permitido «el reinado del materialismo» y la anarquía, agravada hasta el límite con la II República. Hacía falta, a su juicio, «rectificar los errores de un siglo» con un régimen como el suyo, que había de beber en las fuentes de «nuestras tradiciones, nuestras instituciones, nuestra alma [...], fuentes que habían sido perdidas o contaminadas por el liberalismo», y retornar así a las grandezas de la España imperial.

Resulta muy interesante cómo el dictador habla del liberalismo como "farsa extranjerizante" controlada por una oligarquía pues enlaza perfectamente 
con las tesis del movimiento identitario mundial que Bannon quiere unir y organizar (globalistas versus identitarios). De tal modo, observamos una continuidad de las ideas del pasado reaccionario en el presente político.

Soto (2017: 231) insiste en la idea de que las fuerzas que se alzaron contra la II República y que llevaron al general Francisco Franco al poder siempre tuvieron como aspiración la constitución de una nación católica existencial, de tal manera que se hiciera imposible avanzar hacia un sistema asentado sobre una dinámica de soberanía popular, propia de los sistemas liberales.

Siguiendo este hilo, entramos, pues, en el terreno de la abstracción (universal, esencia eterna, nación católica existencial, etc.) cuya categoría integra la España de los eslóganes de Vox.

Con respecto al eslogan "Hacer grande a España otra vez", se observa que es un calco del célebre lema que popularizó Donald Trump en su campaña presidencial de 2016 (“Make America great again”). Ante las preguntas de los medios sobre esta copia, Rocío Monasterio, portavoz de Vox, explicaba (Espada, 2019):

Nosotros no estamos copiando a Trump porque nosotros no queremos hacer América grande, nosotros aspiramos a hacer a España grande. Y para eso hay que seguir el sentido común con valentía como propone VOX: decir la verdad, hacer cumplir las leyes, proteger nuestras fronteras, fortalecer nuestra defensa nacional, enfrentarse a las fuerzas que quieren destruir nuestra nación, luchar contra quienes quieren acabar con la democracia en España, potenciar la educación de nuestros hijos, inculcar los valores que mejor nos preparan para el mundo, la responsabilidad, el esfuerzo, el servicio a la sociedad, la competencia... ¿Qué hay de malo en querer lo mejor para España?. 
El eslogan original de Trump ya era de por sí polémico al incluir a todo el continente americano, cuando en realidad solo se refería a Estados Unidos. Al trasladarlo literalmente al español, Vox no puede evitar implicar que asume los postulados de Trump: una fuerte política antiinmigratoria y proteccionismo económico, entre otras cuestiones de geopolítica como su hostilidad frente a la UE. Precisamente, Santiago Abascal asistió en Washington al discurso de clausura del presidente de Estados Unidos, Donald Trump, en la Conferencia de Acción Política Conservadora (CPAC), el encuentro que reúne al movimiento conservador del país norteamericano desde hace más de 40 años e hizo las siguientes declaraciones (Europa Press, 2020):

Compartimos que el futuro pertenece a los patriotas, no a los globalistas, su mensaje en defensa de los intereses nacionales frente a los organismos supranacionales y su coraje frente a la dictadura de la corrección política.

A la vez, este eslogan implica un contexto propio que abarca la historia de España, implícito en el sintagma nominal de valor temporal "otra vez". Cabría preguntarse qué significa "Hacer España grande otra vez". ¿Cuándo fue España grande? Si se refiere a poder territorial, España fue imperial desde los Reyes Católicos hasta el siglo XIX, cuando se perdieron las últimas colonias en Cuba y Filipinas. Sin entrar en cuestiones históricas, bélicas o éticas, podemos afirmar que los imperios se construyen por la fuerza. Pero, además, el adjetivo "grande" tiene connotaciones históricas, pues fue parte del lema franquista, "Una, grande y libre", refiriéndose a España (figura 7). Su origen fue un artículo de Onésimo Redondo (1955: 135-136), fundador del grupo fascista JONS (siglas de Juntas de Ofensiva Nacional-Sindicalista, más tarde fusionado con Falange), publicado en el periódico Libertad: 
A las balas del poder tiránico sabremos oponer, en unos casos, nuestra astucia; en otros, nuestro coraje, y siempre nuestra firmeza y nuestro tesón ideal. Hasta desalojar a los opresores, hasta alcanzar para España un régimen digno, tan grande como los alientos de vuestros pechos. ¡Viva España Única! ;Viva España Grande!;Viva España Libre! ¡¡Abajo el marxismo!!

Pero, ¿por qué piensa Vox que España no es grande? En este sentido, su ideario habla de pérdida de identidad. La configuración de la identidad de un país, de una nación se basa en la asunción de elementos tradicionales impuestos en distintos momentos históricos, como la religión o el idioma (bajo el reinado de los Reyes Católicos, por ejemplo); además de la unión del territorio, pero en el caso de España existe el conflicto territorial con Euskadi y Cataluña, de un gran componente independentista. De hecho, se atribuye el buen resultado electoral de Vox al Proces catalán (Pintor, 2019) y a los disturbios provocados (Ramos, 2019). Este intento de activar una identidad nacional española está en su ideario (López Corhero, 2019) frente a elementos que la amenazarían como la inmigración, la aconfesionalidad, el separatismo o los derechos LGTBI.

Un aspecto importante que cualificaba el nacionalismo español de extracción franquista era la (Giménez, 2015: 17):

(...) preocupación continua por el pasado y su diversa y acomodaticia interpretación en función del presente. El nacionalismo va a servir, de esta forma, como aglutinante ideológico a través del cual va a ser posible una reinterpretación de la historia de España que viniera a rescatar los aspectos que más interesaban al régimen: la unidad nacional, la construcción del imperio, las gestas de los héroes y las hazañas patrióticas. Se pasará a sobreestimar unos elementos (Viriato, el Cid, los Reyes 
Católicos) y a olvidarse de otros aspectos que no convenían al discurso.

Entrando en el estricto análisis lingüístico del eslogan, este se compone de un verbo en infinitivo (hacer) que tiene como sinónimos construir, producir o elaborar, etc., porque implica que no existe actualmente una España grande y que con la acción del infinitivo Vox pretende revertir la situación. La ausencia de un verbo conjugado que pudiera incluir perifrásticamente el infinitivo "hacer" nos impide catalogar con total seguridad el acto de habla de pertenencia, pero sí podemos afirmar que como eslogan político hace una promesa. Además, apela al receptor por el uso de esa forma no personal del verbo que generaliza el ámbito de inclusión, entrando en el terreno perlocutivo: el receptor se siente incluido a participar en ese proyecto de engrandecer su país. Por tanto, estaría entre el compromisorio y el directivo, según la clasificación de Searle (1969).

El adjetivo grande va pospuesto al sustantivo (España) con lo que podría tener un valor de tamaño; sin embargo, debe tener el valor de calidad propio de los adjetivos antepuestos como: chico grande/gran chico. Pero el adjetivo aquí no es complemento del nombre, sino complemento predicativo, el cual realiza una doble función sintáctica, pues complementa tanto al verbo (hacer) como al complemento directo (España), expresando una cualidad, propiedad o estado. La implicatura que inferimos tiene el sentido de calidad. Descartamos, evidentemente, que Vox quiera ampliar las fronteras del Estado.

"Por España", el lema de Vox para las elecciones del 28 de abril, también contenía la palabra que nombra la nación y era igual de escueto y terminante que el nuevo. Este eslogan tenía por objetivo hacer la presentación en sociedad del partido en sus primeras elecciones generales con altas expectativas, tras haber irrumpido en Andalucía apenas cuatro meses antes. El resultado fue que Vox consiguió 2,6 millones de votos (un 10,2\%) y 24 diputados. 
Solamente se compone de un simple y breve sintagma nominal con la preposición "por", que, de entre sus significados, expresa el fin u objeto de nuestras acciones. La implicatura consistiría en que todas las acciones de Vox van encaminadas a ayudar a la nación española. Tal brevedad y economía léxica llevan a la abstracción; en primer lugar, por falta de concreción y, en segundo lugar, porque se traslada un sentido inmaterial al tipo al que pertenece, sustantivo propio, designando una entidad que no se percibe con los sentidos del cuerpo, sino con la mente. De ahí podemos enlazar con el concepto de nación como sentimiento, lo que discursivamente nos lleva al populismo (Fernández Riquelme, 2020).

La omisión del verbo dificulta la categorización dentro de la tipología de actos de habla de Searle (1969), como ocurrirá con el siguiente y último eslogan. "Por España", ¿qué?: ¿trabajaremos? El uso de este verbo o un sinónimo en futuro equivaldría a un compromiso de futuro del emisor, una promesa. Si el verbo estuviera en presente ("Yo trabajo por España", por ejemplo) el acto ilocutivo estaría más cercano a la aserción porque el hablante o emisor afirma algo con diferentes grados de certeza; está comprometido con la verdad de una proposición.

Este lema fue usado durante un mitin de Vox en Mallorca por Javier Ortega-Smith ${ }^{3}$, Secretario General de VOX, reproduciendo el fragmento titulado "Brindis de los tercios" de la obra de Eduardo Marquina En Flandes se ha puesto el sol (1909):

¡Por España; y el que quiera/defenderla, honrado muera;/y el que, traidor, la abandone/no tenga quien le perdone,/ni en tierra

\footnotetext{
${ }^{3}$ https://twitter.com/TomellosoVox/status/1056541152860614656?ref_src=twsrc\%5Etfw\%7Ctwcamp $\% 5$ Etweetembed\%7Ctwterm\%5E1056541152860614656\&ref_url=https\%3A\%2F\%2Fwww.abc.es\%2Fhisto ria $\% 2$ Fabci-youtube-espana-verdad-sobre-brindis-tercios-flandes-utiliza-arengas-

201901100208 noticia.html
} 
santa cobijo,/ni una cruz en sus despojos,/ni las manos de un buen hijo/para cerrarle los ojos!

A pesar de la épica arenga que se puede escuchar en el video del mitin, el diario conservador ABC (Cervera, 2019) niega la intención patriótica del texto de Marquina:

(...) la intención del autor de la obra no tiene intenciones patrióticas. Entre su lealtad a esta infantería o a su amor flamenco, Eduardo Marquina deja claro que el afecto por las personas siempre prevalece y que el futuro no son los enredos de sus padres, sino Albertino, el hijo fruto de las dos sangres y las dos lealtades.

Es claro que Ortega-Smith no cita a Marquina, sino al uso constante que se hizo durante la época franquista de este tipo de expresiones.

Encontramos otra referencia histórica para un posible origen de este eslogan, y es la expresión "Caídos por Dios y por España”, que encabezaba las placas de homenaje colocadas al final de la Guerra Civil en miles de iglesias, lápidas o monolitos (figura 4). El origen de estas placas fue cuando la Jefatura del Estado de la zona franquista proclamaba el 20 de noviembre como día de luto por la muerte de José Antonio Primo de Rivera, jefe de la Falange Española que fue capturado, condenado y ejecutado por conspirar contra el Gobierno de la Segunda República en 1936. Ese decreto establecía que "previo acuerdo con las autoridades eclesiásticas" en "los muros de cada parroquia figurará una inscripción que contenga los nombres de sus Caídos, ya en la presente Cruzada, ya víctimas de la revolución marxista" (Cabrera, 2014). Estos lemas fueron un eficaz elemento propagandístico, movilizador y conformador de la mentalidad del bando sublevado durante la Guerra Civil española (1936-1939). El uso exaltado, 
emocional y épico en pos de un nacionalismo español parece coincidir, al menos en su fuerza ilocutiva expresiva, con este lema franquista.

El eslogan "España siempre" parece tener su origen como reacción al presentado por el PSOE, “Ahora, España”. En el momento de anunciar el lema de Vox, Santiago Abascal se refirió explícitamente al eslogan socialista para dar una respuesta: "¿Ahora España? No, ahora Vox, España siempre", escribió en Twitter (Carvajal, 2019a). El juego contrastivo con los adverbios de tiempo es evidente. La implicatura principal que sugiere la pregunta retórica de Abascal es achacar al PSOE una preocupación por España solo en campaña electoral, frente al significado del adverbio "siempre", el cual garantizaría que Vox ha tenido en todo momento la prioridad de la defensa de los intereses de la Nación. En esta frase compuesta sintácticamente por un adverbio de tiempo (siempre) y un sustantivo propio, un topónimo (España), se omite cualquier forma verbal. Según la definición de la RAE, "siempre" significa "En todo o en cualquier tiempo"; es decir, aunque tiene un alcance indefinido, manifiesta una preocupación por España que tiende al infinito, al máximo. En consecuencia, este adverbio implementa un matiz expresivo a la fuerza ilocutiva cercano a la pretensión y a la hipérbole.

Sobre el eslogan del PSOE (“Ahora, España”), al que se refiere Abascal, nos encontramos ante una frase compuesta sintácticamente por un adverbio de tiempo (Ahora), una pausa en forma de coma y un sustantivo propio, un topónimo (España). Se omite el verbo lo cual resalta más el valor de las dos palabras. Se llama coma de elipsis o coma elíptica a la que se emplea para indicar que se ha omitido el verbo en una oración que normalmente lo llevaría, por haber sido mencionado antes o estar sobrentendido. En eslóganes y en los aforismos de estructura bimembre, la coma separa ambos elementos. En titulares con una estructura idéntica a las aposiciones también hay una coma: "Un hombre, un voto".

La omisión de la coma en los eslóganes de Vox puede ser gramaticalmente correcta y no pierde fuerza ilocutiva, además de ser totalmente 
comprensible, pues apela al sentimiento y no a la razón al no ofrecer argumentos, cosa que sería difícil de articular en el espacio de un eslogan.

En la siguiente tabla queremos resumir y comparar la manifestación de los elementos pragmáticos de los eslóganes analizados, entre ellos el sentido de la implicatura emanado por cada uno de ellos.

\section{Tabla 2}

Pragmática de los eslóganes analizados

\begin{tabular}{|c|c|c|c|}
\hline Eslogan & Acto de habla & Fuerza ilocutiva & Implicatura \\
\hline $\begin{array}{l}\text { Hacer grande a España otra } \\
\text { vez }\end{array}$ & compromisorio & directiva & calidad \\
\hline Por España & compromisorio & directiva & $\begin{array}{l}\text { identidad- } \\
\text { trabajo }\end{array}$ \\
\hline España siempre & compromisorio & expresiva-directiva & identidad \\
\hline
\end{tabular}

Los eslóganes pertenecen al mundo publicitario y cada uno refiere una modalidad oracional distinta (interrogativa, exclamativa, etc.), aunque el objetivo es el mismo en todos: persuadir y manipular (Carrillo, 2009). En este sentido, Catalá (2000) focaliza la pragmática de los eslóganes en sus efectos y afirma que:

La publicidad pretende hacer que alguien responda de una forma determinada a los estímulos comunicativos contenidos en el mensaje publicitario: la persuasión y la manipulación han sido considerados dos de los principios básicos de esta modalidad de comunicación de masas. Este "querer que otros hagan" se traduce en actos de habla, en concreto en actos de habla perlocutivos. 
Según Austin (1962: 145), los actos perlocucionarios son "los que producimos o logramos porque decimos algo, esto es, consecuencias o efectos sobre los sentimientos, pensamientos o acciones del auditorio".

Por ello, como eslóganes de campaña electoral, Vox los utiliza en dos ámbitos pragmáticos: el acto de habla corresponde a una promesa, su fuerza ilocutiva oscilará entre la expresiva y la directiva (apelativa), cuya realización busca producir unos efectos perlocutivos concretos en el ciudadano desencantado con ciertos parámetros socio-políticos ya tratados en este artículo. La fuerza ilocutiva debe ser directiva pues la finalidad es pedir el voto; equivaldría a "Vótanos":

- Vótanos para hacer una España grande otra vez

- Vótanos por España

- Vótanos para trabajar por/defender a España siempre

En este sentido, estaríamos hablando de actos de habla indirectos. Recordamos que cuando el acto de habla locutivo no coincide con el acto de habla ilocutivo, hablamos de actos de habla indirectos, es decir, donde hay un mensaje indirecto detrás de un enunciado y una intencionalidad diferente a la del sentido literal por la parte del hablante (Searle, 1969). Los actos de habla indirectos son inferenciales porque la fuerza ilocutiva (cómo debe interpretarse el enunciado) depende de la competencia comunicativa del oyente. El hecho de que el acto de habla compromisorio de estos eslóganes no coincida con su fuerza ilocutiva no invalida la promesa, porque socialmente el ciudadano conoce el contexto de campaña electoral y propaganda política en el que estos se formulan y relativiza el hecho de que la clase política cumpla o no sus promesas. En este caso, las promesas son de carácter abstracto y por tanto es difícil medir cuantitativamente su grado de cumplimiento, aunque, precisamente por ello, pueden ser más efectivas dado que su objetivo es activar y atraer una conciencia 
patriótica con mensajes fáciles de procesar cognitivamente. Los receptores atraídos, los votantes no computarán materialmente esas promesas, sino simbólicamente, les están llamado a participar en un proyecto en el que lo inmaterial, los sentimientos (historia, religión, bandera, patria...) son parte fundamental para sentirse incluidos en una comunidad cuyos valores estiman en proceso de desaparición y con ellos su propia identidad.

\section{Conclusiones}

Los tres eslóganes coinciden en la inclusión del término España como idea, no considerándola en su valor de topónimo, sino tomándola como inmaterial. Esta abstracción conlleva la falta de elementos concretos como una promesa de carácter material (vivienda, empleo, pensiones...) o incluso con matices inmateriales (seguridad, educación...), y el espacio de unas elecciones generales da pie a prometer cualquier elemento que pudiera mejorarse en la sociedad a la que se dirige. Por tanto, hay una ausencia de ideas manifiesta.

Esa categoría abstracta, pues apela a España, pero no a los españoles, es usada como sinónimo de patria, buscando en la nación española una realidad sustancial, aunque ancestral, tradicional y legendaria (Fernández Riquelme, 2020). De hecho, Vox abrió su campaña electoral para las elecciones generales de abril de 2019 en el Santuario de Covadonga, donde según la tradición el Rey Don Pelayo, de la tribu astur, ganó en el año 722 la primera batalla a los pueblos musulmanes que invadieron la Península lbérica a partir del 711, dando lugar al comienzo de la llamada Reconquista. Dos titulares (y subtítulos) de prensa lo expresaban así:

\section{-Abascal lanza desde Covadonga su cruzada contra separatistas y "progres"}

(González, 2019) 
El líder de Vox congrega a varios cientos de personas bajo la estatua de Don Pelayo.

\section{-Éxtasis patriótico de Vox en Covadonga: "No vamos a pedir perdón por la historia ni los símbolos}

(Carvajal, 2019)

Acompañado por una multitud y entre gritos y vivas a España, Santiago Abascal ha dado su mitin de campaña a los pies de la estatua de Don Pelayo, símbolo de la Reconquista.

Si seguimos la definición del pueblo populista de Villacañas (2015: 28), Vox estaría construyendo ese pueblo, pues este sería una:

(...) comunidad construida mediante una operación hegemónica basada en el conflicto, que diferencia en el seno de una unidad nacional o estatal entre amigos/enemigos como salida a la anomia política y fundación de un nuevo orden.

Ellos/los otros son los enemigos de España (nacionalistas periféricos, izquierdistas, feministas, inmigrantes, colectivo LGTBI, etc.), pero suponen un conglomerado demasiado grande y heterogéneo, cuando el populismo busca entre las élites políticas y económicas al enemigo. Vox no lo hace, por más que pueda apuntar demasiado tímidamente a algún proteccionismo económico o a la Unión Europea; al contrario que el Front National, la Lega o el partido del húngaro Viktor Orban, mucho más beligerantes con ella. Es evidente que la apelación a España como patria y nación ancestral en lo ideológico se dirige a las emociones, no a la razón. Apela a las pasiones para movilizar a un electorado que, más allá de sus propuestas políticas concretas, pueda sentirse unido en torno a una 
construcción sentimental frente a los procesos separatistas y al desgaste de los partidos tradicionales.

España sería el significante vacío de Laclau (2005), donde cabrían las demandas insatisfechas de un sector importante de la población y que pretende activar esa operación hegemónica. Otra característica del populismo es la identificación del líder/partido con el pueblo/patria (Charaudeau, 2009). Vox opta en sus eslóganes por esa equivalencia entre el partido y la nación entendida como patria, y esta como único valor capaz de mover al ciudadano.

Si aplicamos la teoría de la relevancia de Sperber y Wilson (2004) en los tres eslóganes de Vox, observamos que cada enunciado es relevante porque su efecto cognitivo en relación con el contexto es sumamente eficaz por:

- La crisis de soberanía nacional presente en la conciencia colectiva por el Proces independentista catalán.

- Irrupción de un partido a la izquierda del PSOE capaz de disputar el poder (nacional, local o autonómico) como es Podemos.

- Problemas en el seno de la Unión Europea.

- Fuerte concienciación feminista.

- Inmigración.

La reacción cognitiva y emocional de determinados sectores sociales no identificados con uno o varios de estos elementos, moviliza una adscripción política con Vox. Así, el uso del término España con pocos elementos adjuntos requiere un escaso esfuerzo de procesamiento mental, lo que facilita esa misma identificación.

Más allá de las etiquetas que se le atribuyen (populistas, extrema derecha/ultraderecha, derecha radical...), los autores mencionados coinciden en que Vox y los partidos afines europeos no han creado o no pertenecen a una nueva categoría política, sino que siguen la línea de los partidos que surgieron 
de las cenizas del fascismo, pero que se alejaron del totalitarismo como forma de gobierno y acción política. Se mantendrían características como el racismo, las hostilidades contra las minorías, el ultranacionalismo y el anticomunismo. Vox añadiría un elemento propio del fascismo español, llamado históricamente como "nacional-catolicismo", por la importancia de la confesión cristiana en su ideología. Además, el partido liderado por Abascal extendería ese anticomunismo a la "dictadura pogre"4:

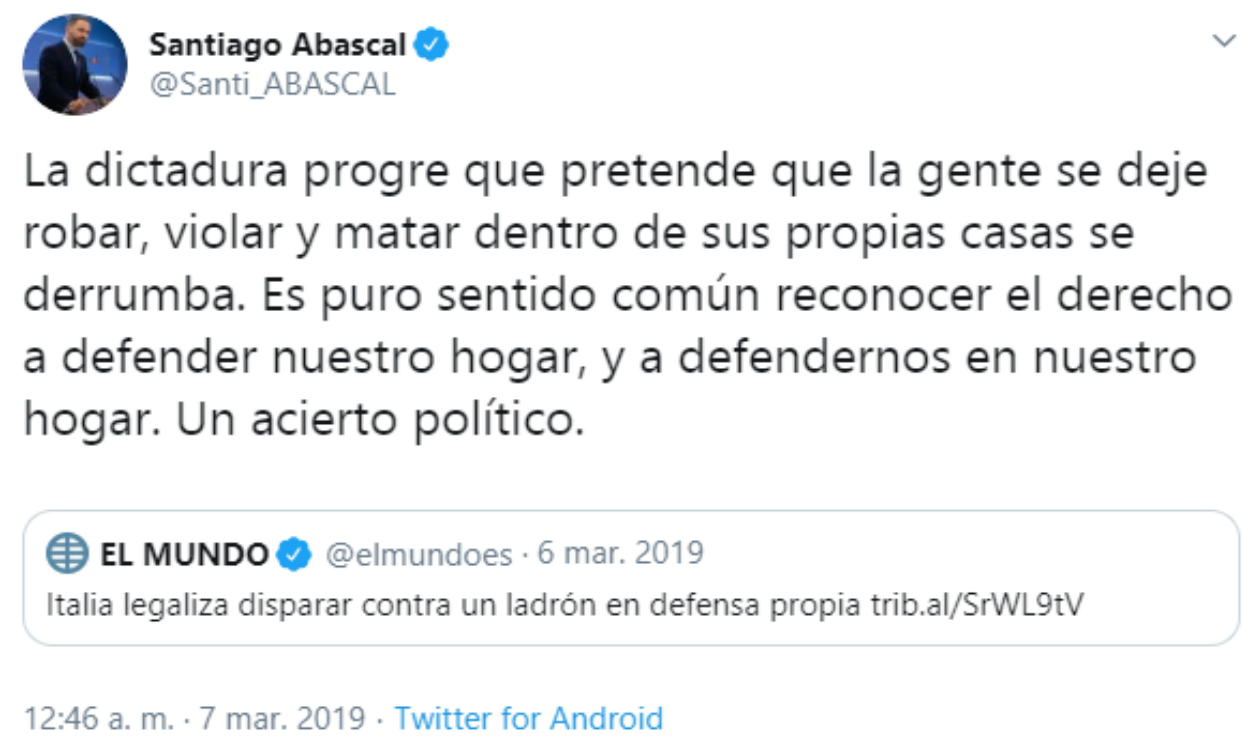

Esta concepción parcial de España emana del pensamiento reaccionario español que tuvo un especial vigor durante el franquismo pues "no había otra visión de España ni a esta se la podía servir desde otros planteamientos políticos, lo que incrementaba las perspectivas de obediencia sin discusión al régimen (Giménez, 2015: 25).

Como conclusión, podemos afirmar que estos tres eslóganes tienen un parecido significativo con algunos lemas del franquismo por el significante, pero cobran un especial sentido si los relacionamos con el contexto discursivo actual. Los dos ejes semánticos que articulan las palabras que componen los eslóganes son la identidad (España como patria eterna y como comunidad indivisible) y la nostalgia (grande; otra vez). Su fuerza ilocutiva bascula entre la expresiva y la

\footnotetext{
${ }^{4}$ https://twitter.com/Santi_ABASCAL/status/1103441700519899136
} 
apelativa, como manifestación de deseo y como llamada para activar un sentimiento nacionalista excluyente entre los receptores, potenciales votantes. Ese sería el efecto perlocutivo que conseguiría el voto.

\section{Bibliografía}

ANTEQUERA, J.

2019. "El programa económico de Vox da miedo". Diario16. Consulta 09/04/2019, de https://diario16.com/el-programa-economico-de-vox-damiedo/.

AUSTIN, J. L.

1962. Cómo hacer cosas con palabras: Palabras y acciones. Barcelona: Paidós, 1990.

\section{BASTANTE, J.}

2018. "Las conexiones de Vox con HazteOir, los 'kikos' y una docena de obispos españoles". Eldiario. Consulta 7-12-2018, de https://www.eldiario.es/sociedad/conexiones-Vox-gruposultracatolicos_0_843766322.html

CABRERA, E.

2014, “José Antonio Primo de Rivera, ipresente!". Eldiario. Consulta 13-04-2014. https://www.eldiario.es/sociedad/Jose-Antonio-presente_0_248475769.html CACHERO, G.

2018. "Tres focos del ascenso de la extrema derecha en Andalucía". El país. Consulta 4/12/2018. https://elpais.com/politica/2018/12/03/actualidad/1543851289_718405.h tml 
CARVAJAL, A.

2019a. "Vox rivaliza con el PSOE y responde a su lema de campaña con el eslogan "España siempre". El mundo. Consulta 1/10/2019.

https://www.elmundo.es/espana/2019/10/01/5d933442fdddffad598b45e9 .html

2019b. "Éxtasis patriótico de Vox en Covadonga: "No vamos a pedir perdón por la historia ni los símbolos". El mundo. Consulta 12/4/2019.

https://www.elmundo.es/espana/2019/04/12/5cb0b30921efa00e068b45e 5.html

CARBAJOSA, A.

2019. "Los ultras europeos, entre el poder y el cordón sanitario". El país. Consulta $17 / 11 / 2019$.

https://elpais.com/internacional/2019/11/16/actualidad/1573911285_75041 2.html

CARRILLO, P.

2009. El eslogan electoral español (1975-2000). Estructuras fundamentales. Tesis doctoral. Universidad de Murcia.

CATALÁ, M.

2000. "La comunicación publicitaria", [en línea] 5campus.org, Sociología:

http://www.5campus.org/leccion/socio001

CERVERA, C.

2019. «¡Por España!»: la verdad sobre el brindis de los Tercios de Flandes que utiliza VOX en sus arengas". Consulta 12/11/2019.

https://www.abc.es/historia/abci-youtube-espana-verdad-sobre-brindistercios-flandes-utiliza-arengas-201901100208_noticia.html 
CHARAUDEAU, $P$.

2009. Reflexiones para el análisis del discurso populista. Discurso \& Sociedad, $3(2): 253-279$

CHOMSKY, N. y HERMAN, E.

1988. Los guardianes de la libertad. Barcelona: Crítica.

ESPADA, K.

2019. "El significado del eslogan de Vox". Diario Siglo XXI. Consulta 30/09/2019.

http://www.diariosigloxxi.com/texto-diario/mostrar/1402846/significadoeslogan-vox

\section{EUROPA PRESS}

2020." Abascal se cita con el hijo de Bolsonaro y con la derecha de EE. UU. en su gira americana". El confidencial. Consualta 29/02/2020

https://www.elconfidencial.com/espana/2020-02-29/abascal-discurso-detrump-futuro-pertenece-patriotas-no-

globalistas_2476296/?utm_source=facebook\&utm_medium=social \&utm_campaign=ECFindeAutomatico\&fbclid=IwAR2KIUZiqalr9gt8 5BbnlsMPX0H8cc0x6Z2pXhY6nJ6vsskzi2w-B1-gyzM

\section{FÁBREGAS, L.}

2018. "Los tres fundadores de Vox que abandonaron el partido por su deriva euroescéptica y católica". Crónica global. Consulta 1-II-2020.

https://cronicaglobal.elespanol.com/politica/fundadores-vox-abandonaronpartido-deriva-nacionalista_204561_102.html

\section{FABREGAT, R.}

1961. Propaganda y sociedad. México: Instituto de Investigaciones Sociales. 


\section{FERNÁNDEZ, G.}

2019. Qué hacer con la extrema derecha en Europa. El caso del Frente Nacional. Lengua de trapo.

\section{FERNÁNDEZ RIQUELME, P.}

2020. "La retórica del discurso populista". Refracción, n¹, enero-junio, 14-24.

FERNÁNDEZ, A. y SEGOVIA, M.

2019. "Ha vuelto la Antiespaña. VOX y su violencia discursiva". El salto. 19 de abril de 2019. Recuperado de:

https://www.elsaltodiario.com/historia/ha-vuelto-la-antiespana-vox-y-suviolencia-discursiva

FERREIRA, C.

2019. "Vox como representante de la derecha radical en España: un estudio sobre su ideología". Revista Española de Ciencia Política, 51: 73-98.

GALLARDO, B.

2018. Tiempos de hipérbole. Inestabilidad e interferencias en el discurso político. Valencia: Tirant.

GARCÍA, P.

2019. "Sánchez se dirige a Rivera en su réplica a Abascal: "¿Lo escucha? Es la ultraderecha". El independiente. Consulta 22/7/2019.

https://www.elindependiente.com/politica/2019/07/22/sanchez-dirigerivera-replica-abascal-escucha-ultraderecha/

GIL, A.

2019. "Steve Bannon: el míster Marshall que no logró unificar la extrema derecha europea y que puede acabar desalojado de Italia". Eldiario. Consulta 12/06/2019.

https://www.eldiario.es/internacional/Steve-Bannon-Mr-Marshallextrema_0_909209718.html. 
GONZÁLEZ, M.

2109. "Abascal lanza desde Covadonga su cruzada contra separatistas y progres". El país. Consulta 12/4/2019.

https://elpais.com/politica/2019/04/12/actualidad/1555085458_659820.ht $\mathrm{ml}$

\section{GONZÁLEZ CUEVAS, P.}

2009a. "En torno a la derecha identitaria". Kosmópolis. 1 de agosto de 2019. http://www.kosmospolis.com/2019/08/en-torno-a-la-derecha-identitaria/

2009b. "El dilema de Vox: neoliberalismo o derecha identitaria" Disidentia. 21 de noviembre de 2019. Recuperado de:

https://disidentia.com/el-dilema-de-vox-neoliberalismo-o-derechaidentitaria/

\section{GIMÉNEZ, M. A.}

2015. "El corpus ideológico del franquismo: principios originarios y elementos de renovación". Estudios Internacionales, 180: 11-45.

GRICE, H. P.

1975. “Lógica y conversación”. En Valdés, L. La búsqueda del significado. Madrid: Tecnos/Universidad de Murcia, 1991, 511-530.

GUIMÓN, P.

2019. "Trump, en la ONU: "El futuro pertenece a los patriotas, no a los globalistas". El país. Consulta 2019/09/24

https://elpais.com/internacional/2019/09/24/actualidad/1569343093_53421

8.html. 
HOSENBALL, $\mathrm{M}$.

2018. "El asesor que llevó a Trump a la Casa Blanca lanza un movimiento ultra para derribar las instituciones europeas”. Público. Consulta 23/7/2018. https://www.publico.es/internacional/asesor-llevo-trump-casa-blancalanza-movimiento-ultra-derribar-instituciones-europeas.html

LACLAU, E.

2005. La razón populista. Madrid: Siglo XXI.

LAKOFF, G.

2007. No pienses en un elefante: Lenguaje y debate político. Madrid: Editorial Complutense.

LLAMAS, M.

2018. "El programa económico de VOX, luces y sombras". El debate de hoy. Consulta 18/12/2018.

https://eldebatedehoy.es/economia/programa-economico-de-vox/

LLANERAS, $\mathrm{K}$.

2018. "Vox crece donde hay más inmigrantes: un mapa de sus votos en cada municipio". El País. Consulta 3/12/2018:

https://elpais.com/politica/2018/12/03/actualidad/1543829876_200181.ht $\mathrm{ml}$

LÓPEZ CORHERO, J.

2019. La "Vox" de la representación - Un análisis de discurso. Trabajo final. Universidad del País Vasco. Recuperado de:

https://www.researchgate.net/publication/337388371_LA_VOX_DE_LA_R EPRESENTACION_-_Un_analisis_de_discurso 
MUDDE, C.

2000. The ideology of the extreme right. Manchester: Manchester University Press.

PINTOR, M. J.

2019. "El conflicto catalán benefició a Vox en las elecciones". Diario 16. Consulta 29/11/2019.

https://diario16.com/el-conflicto-catalan-beneficio-a-vox-en-laselecciones/

RAMOS, A. B.

2019. "Los disturbios en Cataluña reafirman a Vox como tercera fuerza en las encuestas". El independiente. Web. 20/10/2019.

https://www.elindependiente.com/politica/2019/10/20/los-disturbios-encataluna-reafirman-a-vox-como-tercera-fuerza-en-las-encuestas/

REDONDO, 0 .

1955. "La España que hace política”, Libertad, 49, 16 de mayo de 1932 en Obras completas, tomo II, pp: 135-136. Madrid: Publicaciones Españolas. [Dirección General de Información].

\section{RODRÍGUEZ, R.}

2019. "El programa económico de Vox, analizado por un técnico de Hacienda: bueno para las rentas altas, malo para el resto". Eldiario. Web. 22/04/2019.

https://www.eldiario.es/economia/programa-economico-Voxrealidad_0_891361447.html

RODRÍGUEZ PALOP, M. E.

2019. "Vox y la extrema derecha de Bolsonaro". Contexto. 30-I-2019. Recuperado de:

https://ctxt.es/es/20190130/Firmas/24129/vox-bolsonaro-neoliberalismomaria-eugenia-rodriguez-palop.htm 
SANGIAO, S.

2018. "Los orígenes de Vox: el aznarato y la lucha contra ETA". CTXT. Web. 2811-2018.

https://ctxt.es/es/20181129/Politica/23127/vox-aznar-eta-esperanzaaguirre-sergio-sangiao.htm

SEARLE, J.

1969. Actos de habla. Madrid: Cátedra, 2001.

SORIANO, D.

2020. “¿Salvini o Johnson? Cuál será la política económica de Vox”. Libremercado. Web. 15/2/2020.

https://www.libremercado.com/2020-02-15/salvini-o-johnson-cual-sera-lapolitica-economica-de-vox-1276652125/

SOTO, D.

2017. "Nación católica e Imperio en la Filosofía de la Historia de García Morente". La razón histórica, 37: 230-251. Disponible en: https://www.revistalarazonhistorica.com/37-14/ SPERBER, D. y WILSON, D.

2004. "La teoría de la relevancia”. Revista de Investigación Lingüística, VII: 237286.

VILLACAÑAS, J. L.

2015. Populismo. Madrid: La huerta grande. 
2020. "Identidad y nostalgia: el discurso de Vox a través de tres eslóganes"

Sabir. International Bulletin of Applied Linguistics. 1,2: 77-114

\section{ANEXO GRÁFICO}

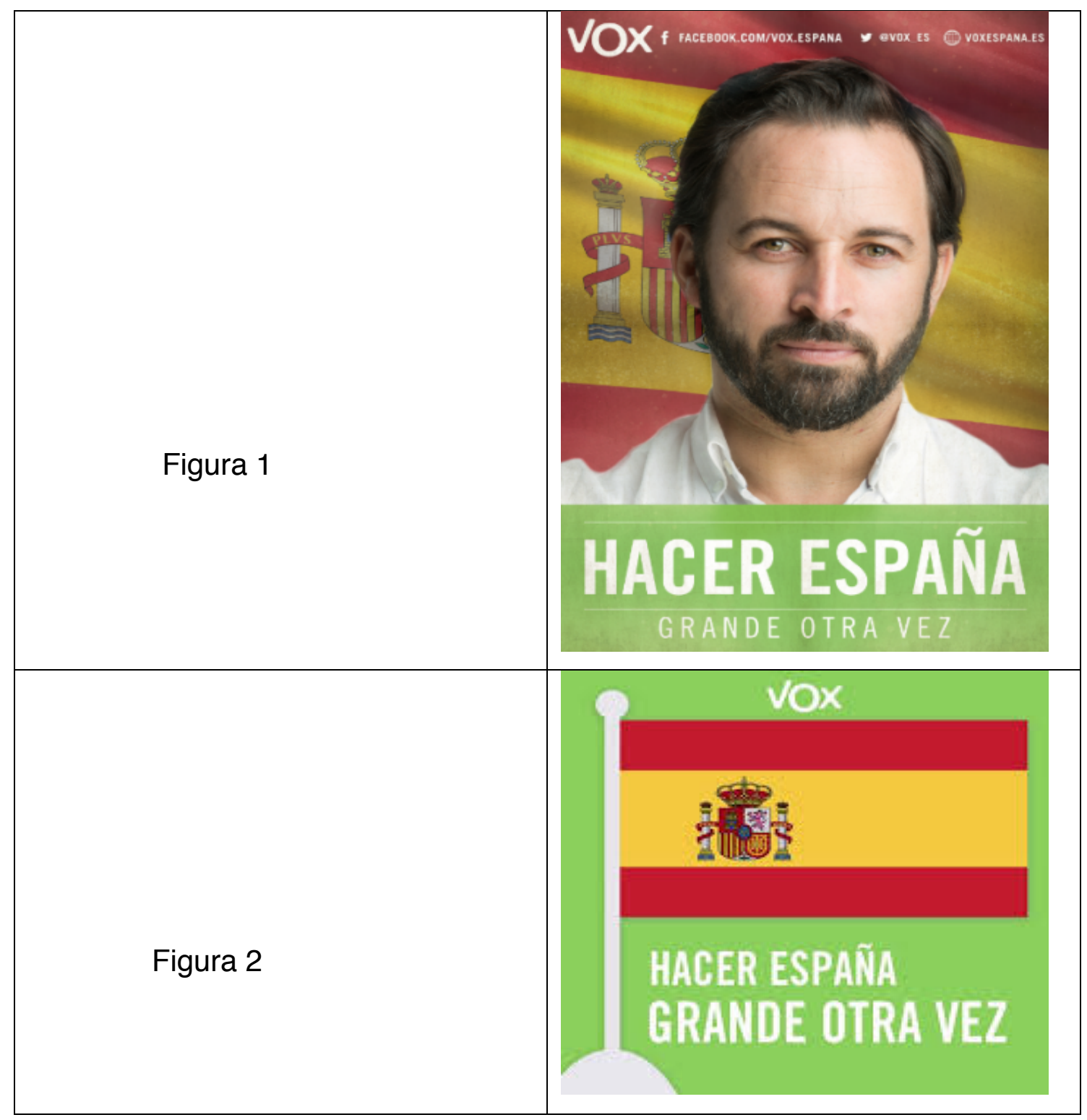


2020. "Identidad y nostalgia: el discurso de Vox a través de tres eslóganes"

Sabir. International Bulletin of Applied Linguistics. 1,2: 77-114
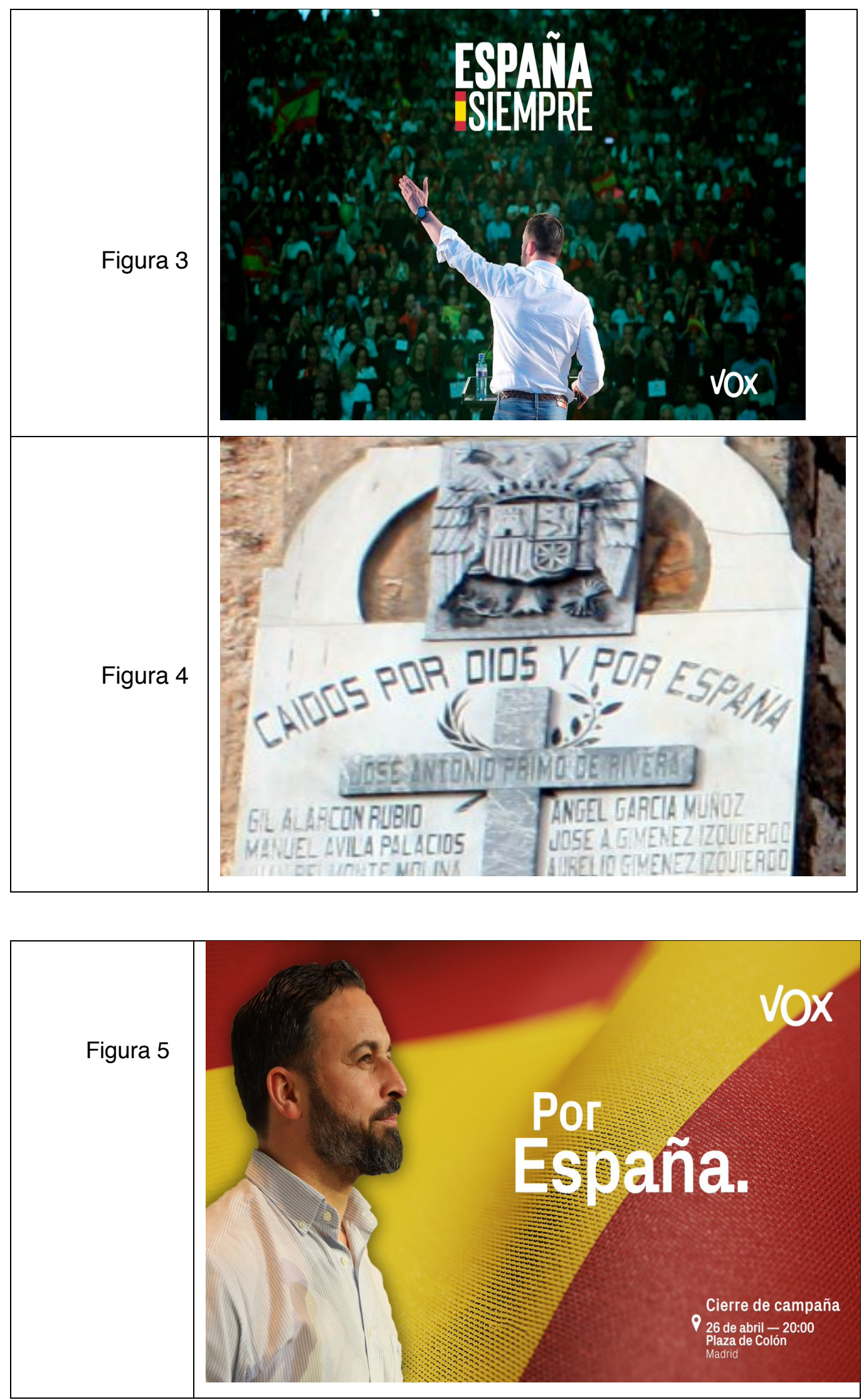
2020. "Identidad y nostalgia: el discurso de Vox a través de tres eslóganes" Sabir. International Bulletin of Applied Linguistics. 1,2: 77-114

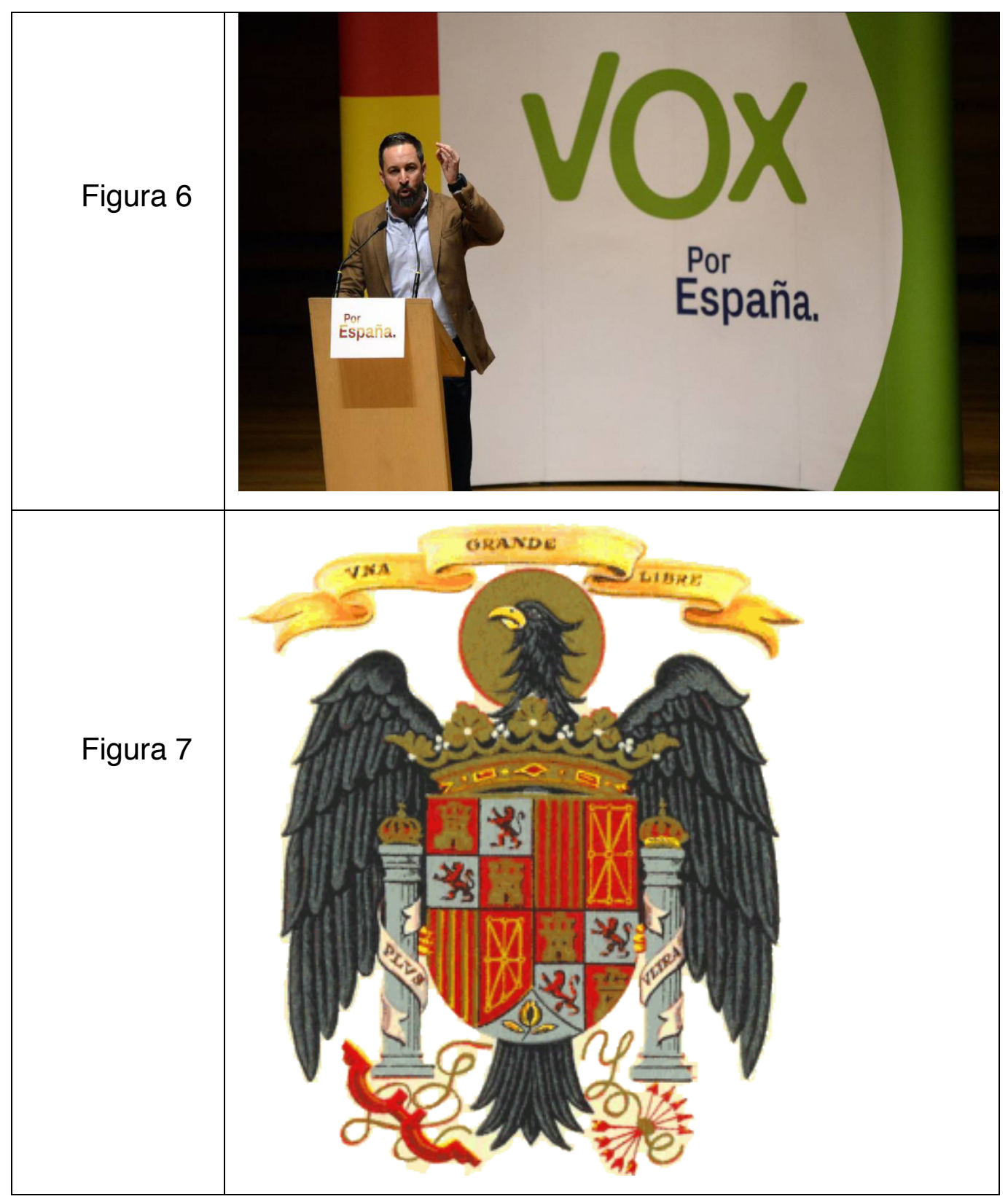


2020. "Identidad y nostalgia: el discurso de Vox a través de tres eslóganes"

Sabir. International Bulletin of Applied Linguistics. 1,2: 77-114

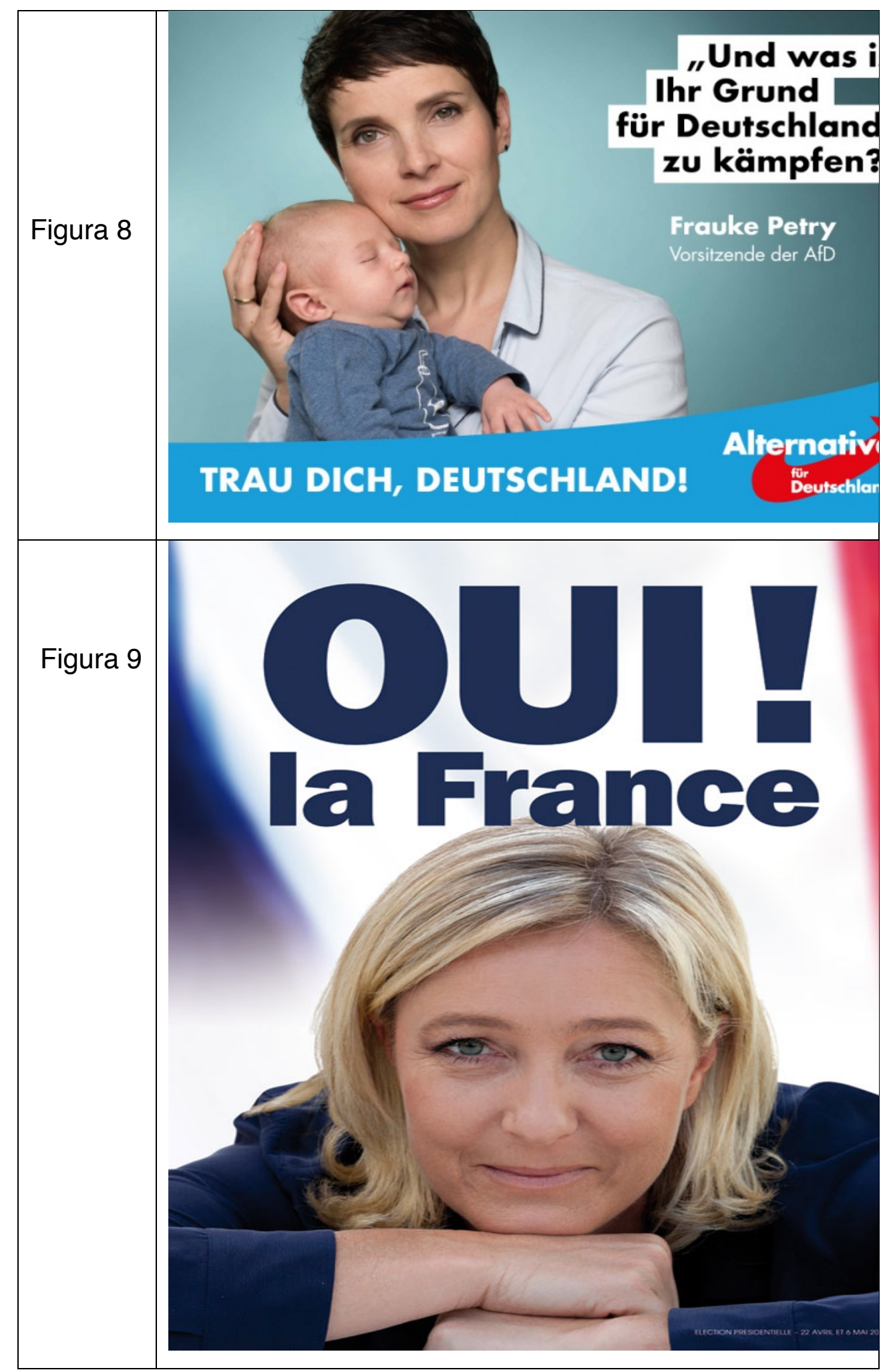


2020. "Identidad y nostalgia: el discurso de Vox a través de tres eslóganes" Sabir. International Bulletin of Applied Linguistics. 1,2: 77-114

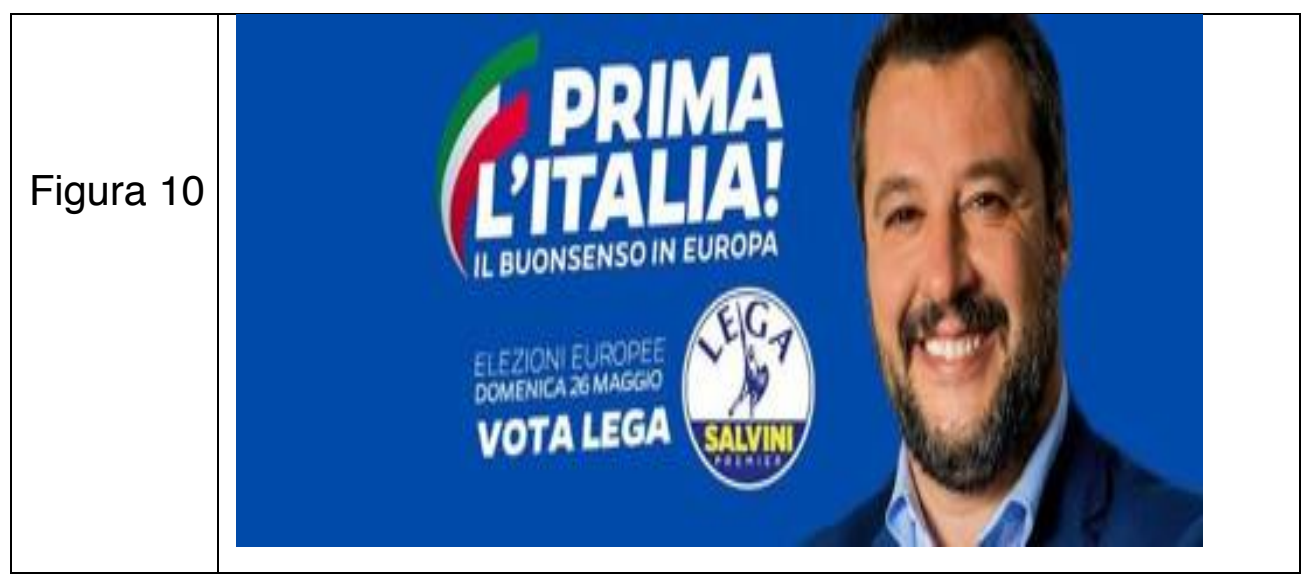

